\title{
Factors Affecting Industry 4.0 Adoption in the Curriculum of University Students in Ho Chi Minh City*
}

\author{
Xuan Truong NGUYEN ${ }^{1}$, Thanh Toan NGUYEN ${ }^{2}$
}

Received: July 18, 2020 Revised: August 23, 2020 Accepted: August 29, 2020

\begin{abstract}
This study investigates the factors affecting Industry 4.0 adoption in the curriculum of university students in Ho Chi Minh City, Vietnam. Universities need to respond to the changing faces of Industry 4.0 and, hence, Education 4.0. A mixed method including both qualitative and quantitative methodologies was utilized. An in-depth interview was carried out for exploring, reviewing, and testing content validity of constructs and measurement items. The pilot study was conducted with 120 respondents. The conceptual model and hypotheses were developed using data collected by a questionnaire survey distributed to 584 respondents by both electronic and paper forms with nonprobability and convenience sampling techniques. The result of structural equation modeling showed that occupation relevance, skills, facility conditions, and social influence impacted on the intermediates variables, namely, relevance advantage, perceived usefulness, behavioral intention-to-use, and actual use. The independent variables are occupation relevance, skills, facility conditions, and social influence. They impact actual use through mediating constructs such as relevance advantage, perceived usefulness, and behavioral intention-to-use. The findings suggest that universities and students' efforts aimed at increasing the factors' perceptions of adoption of Industry 4.0 will contribute to implementation success, where success is defined as effectual usage of Industry 4.0.
\end{abstract}

Keywords: Industry 4.0, College Students, Ho Chi Minh City, Vietnam

JEL Classification Code: J24, D71, D9, M11, M31

\section{Introduction}

Nowadays, we are in the midst of a significant transformation regarding the way we produce products

\footnotetext{
*Acknowledgements:

The paper was presented initially under the title ["Industry 4.0 Adoption on Studying of University Students in Ho Chi Minh City"] at the KODISA 2019 International Conference on Business and Economics (ICBE2019) held in Yeosu, South Korea, July 8-10, 2019. The paper has been recognized as one of Best Paper Awards at the KODISA.ICBE2019 conference. This paper has been substantially revised and expanded. The authors have taken into account the comments of Editors, Session Chairs and Reviewers and greatly appreciate their valuable interest in and support for this research.

${ }^{1}$ First Author and Corresponding Author. Dean, Marketing Department, University of Finance - Marketing, Vietnam [Postal Address: 2/4 Tran Xuan Soan Street, Tan Thuan Tay Ward, District 7, Ho Chi Minh City, 72910, Vietnam] Email: ts.truong@ufm.edu.vn ${ }^{2}$ Second Author. Marketing Department, University of Finance Marketing. Email: thanhtoantnt98@gmail.com

(c) Copyright: The Author(s)

This is an Open Access article distributed under the terms of the Creative Commons Attribution Non-Commercial License (https://creativecommons.org/licenses/by-nc/4.0/) which permits unrestricted non-commercial use, distribution, and reproduction in any medium, provided the original work is properly cited.
}

thanks to the digitization of manufacturing. This transition is so compelling that it is being called Industry 4.0 to represent the fourth revolution that has occurred in manufacturing. Industry 4.0 is a name given to the current trend of automation and data exchange in manufacturing technologies. It includes cyber-physical systems, the Internet of Things, cloud computing, and cognitive computing. Industry 4.0 is not only about potential increases in resource efficiency in manufacturing, or robots harvesting vast amounts of data. It is already happening now and is impacting our life through improved products and services, education, road safety, better working conditions, and even healthcare.

Currently, universities need to align themselves with the changing faces of the Industry 4.0 and, hence, Education 4.0. Universities have to adopt Education 4.0 where the learner is at the center of the education economy. Universities are not only faced with employability challenges, but also working toward managing societal challenges. Therefore, Education 4.0 has to develop ethical business and nurture technology leaders for the future. By now, every student is likely to have heard about Industry 4.0, about the applications and effects that it creates, which is somewhat accessible to be 
studied at universities. Since then, Industry 4.0 has become a hot topic. In Vietnam, there has been no research work on this topic.

In this study, we want to think about it in a reverse way. Instead of studying the impact of Industry 4.0 on aspects of life, we want to investigate deeply what reasons, factors, and other things affect the application of Industry 4.0 in learning. Is it merely because of media that publicity is being mentioned so much that you have to use it or is there any other underlying cause? Hoang Minh Son (2018) discusses the skills needed in the 4.0 Industrial Revolution. This industrial revolution will have impacts on many other fields besides manufacturing, such as workforce recruitment, information, and communication technology (ICT), business, education, and many more. As economics students, we find that Industry 4.0 and business management are more closely connected; the impact of industry on workforce recruitment is expected to be quite significant owing to the requirement to possess some basic technical qualifications in Industry 4.0, including information technology (IT) knowledge, organizational, process understanding, and ability to interact with modern interfaces.

Understanding the impact factors will help the higher education system in general as well as the policymakers look deeper into the core of the problem, understand the reasons for personal adoption of Industry 4.0 in accordance with the school curriculum. In this study, a conceptual model was developed, including occupation relevance, skill, facility conditions, and social influence resulting from previous studies, in order to explain an individual's behavioral intention-to-use and the actual use of Industry 4.0 while studying at Ho Chi Minh City universities.

\section{Literature Review and Hypothesis Development}

\subsection{Occupation Relevance (OC)}

One key component of the matching process discussed above is a potential user's judgment of occupation relevance, which we define as an individual's perception regarding the degree to which the target system is applicable to his or her job. The word 'Occupation Relevance' incorporates the details of the Technology Acceptance Model (TAM2), an extended version of the original TAM (Venkatesh \& Davis, 2000). Their study show that the old theory still holds for modern times, while the additional processes improve the explanatory ability of the model. Occupation relevance or job relevance is based on the system able to support an individual's job function. "An individual's perception regarding the degree to which the target system is applicable to the individual's job. Job relevance is a function of the important within one's job of the set of tasks the system is capable of supporting" (Venkatesh \& Davis, 2000). Kiera and Polson (1985) and Polson (1987) argued that users possess distinct knowledge about their job situation, which they can use as a basis for determining what tasks can be performed with a given system. The existence of welldefined knowledge structures regarding important job goals is supported by research from personnel psychology (Brief \& Roberson, 1989). The researchers regard occupation relevance as a cognitive judgment that exerts a direct effect on relative advantage, distinct from acceptable models. The researchers conceptualize perceptions of occupation relevance to be part of a compatibility test that would be screened from further adoption consideration. So, we would expect the following hypothesis:

H1: Occupation relevance will have a positive effect on relative advantage.

\subsection{Skills (SK)}

Skill is one's ability to apply knowledge and use the know-how for the completion of well-defined tasks. Generally speaking, identifies that an individual is able to do something within a specific context. Skills may be cognitive (involving the use of logical, intuitive and creative thinking) or practical (involving manual dexterity and the use of methods, materials, and tools) (Chryssolouris et al., 2013). In fact, training is seen to contribute to promoting innovation strategy in an organization given that the acquisition of new skills and thinking precedes innovation (Jadhav et al., 2017).

Based on the nature of Internet skills being transferable to new web developments (Van Deursen \& Mossberger, 2018), we expect that they will remain relevant for the Internet of Things (IoT). While originally most attention was on technical skills, in the past years, several skill dimensions or multifaceted conceptualizations have been addressed. A recent framework labeled Internet Skills Scale (ISS) proposed dimensions encompassing, not only the technical ability, but also other skill types focusing on different engagements one can have with the Internet (Van Deursen \& Van Dijk, 2016). The skill types covering the technical ability to use the Internet are operational skills and mobile skills. Information navigation skills comprise the ability to search the Internet, including finding, selecting, and evaluating information sources on the Internet. However, these skills have now been transferred to mobile devices. Mobile skills enable investigating the distribution of skills in using mobile devices, such as downloading and installing applications and monitoring the data costs involved in online mobile use (Van Deursen \& Van Dijk, 2016). In turn, these Web 1.0 skills are a requirement for Web 2.0 skills: social and creative skills. Social skills enable using online communication and interactions to understand and exchange meaning, involving 
searching, selecting, evaluating, and acting on online contacts. Creative skills are the skills necessary to create content suitable for online display. This content can include text, music and video, photo or image, multimedia, or remixed media. Furthermore, creative skills also involve the basics of uploading this content (Van Deursen et al., 2016). Students with good language skills and good technical skills can actively understand and use technology easily. People consider the implications of their actual behavior before they decide to engage or not engage in a given behavior (Ajzen \& Fishbein, 1980). Higher commitment is more likely to mean that behavior would be performed. These skills help users intend to use it in their study and life, skills affect behavioral intentions. The hypotheses are presented as follows:

H2: Skills have a positive influence on perceived usefulness.

H5: Skills have a positive influence on behavioral intention-to-use.

\subsection{Facility Conditions (FC)}

The construct of facility conditions refers to the extent to which individuals believe that both technical and organizational infrastructures exist to support the use of a particular technology (Venkatesh et al., 2003). Facility conditions refer to technical and organizational facilitators that help users to overcome obstacles related to the use of technology. In fact, the effect is expected to increase with experience as users of technology find multiple avenues for help and support throughout the organization, thereby removing impediments to sustained usage (Bergeron et al., 1990). Organizational psychologists have noted that older workers attach more importance to receiving help and assistance on the job (Hall \& Mansfield, 1975). Universities have to focus on enhancing human capital in certain fields of knowledge and on joint efforts to transfer technology through cooperation (Alibekova et al., 2019). The availability of proper facilitating conditions (e.g., training courses, technical support, and adequate resources, devices) is crucial for technology adoption (Aypay et al., 2012). Consequently, guidance and technical support are essential to facilitate students' engagement with e-learning (Concannon et al., 2005). In particular, the functionality of personal mobile devices and support from learning providers appear to be vital factors.

H3: Facility conditions have a positive influence on perceived usefulness.

\subsection{Social Influence (SI)}

Social influence is defined as the degree to which an individual believes that other people whose opinion is important to them think the same way about using a new system. The personal perception that people who are important to them think about him/her using the system (Shore et al., 2018). The degree to which an individual perceives that important others believe they should use the new system (Mejía,2015). According to Mirjana et al. (2015), social influence is the degree to which an individual perceives that others believe they should use a particular system. Especially, the social factor items were adapted as they strongly focused on computer systems in organizations: "The senior management of this business has been helpful in the use of the system" (Osswald et al., 2012). Social influence has an impact on the student's individual perception since the students themself as well as integrated technology are often regarded as a status symbol. We think that the representative character and the properties and features of information technology can foster identification and highlight the connection between acceptance and the social environment. In this study, social influence is also affected by social media, which is a means for people to share their photos, post statuses, update their daily lives and communicate with other people, thus deriving a sense of self-assurance and belonging. Social media has been powerful in changing the way people connect with one another and has brought many positive outcomes (Nguyen, 2018; Nguyen, 2019).

H4: Social influence has a positive influence on perceived usefulness.

\subsection{Perceived Usefulness (PU)}

Perceived usefulness is defined as the extent to which persons believe that technology will enhance their productivity or job performance (Davis et al., 1989). In the student context, it is the perceived likelihood that the technology will benefit the person in the performance of some tasks. It is concerned mainly with perceptions of the functional outcome as a consequence of technology usage. A significant body of TAM research has shown that perceived usefulness is a strong determinant of user acceptance, adoption, and usage behavior (Davis, 1989; Mathieson, 1991; Taylor \& Todd, 1995). In fact, perceived usefulness has been found to be the most significant factor in the acceptance of technology in the study place, even more, important than perceived ease-of-use (Davis, 1989; Nguyen \& Luu, 2020). In the consumer context, significant positive relationships have been found between the perceived usefulness of new Internet services and attitudes toward these services (Childers et al., 2001; Gentry \& Calantone, 2002). Similarly, perceived usefulness has been found to have a positive impact on attitude toward using mobile Internet products (Bruner \& Kumar, 2005; Kim et al., 2003). Therefore, the following hypothesis was examined: 
H6: Perceived usefulness has positive significance on the intention-to-use.

\subsection{Relative Advantage (AR)}

According to Rogers (2010), five key factors that influence an individual's decision to adopt or reject an innovation include relative advantage, compatibility, complexity/simplicity, trialability, and observability. "Relative advantage" identifies how improved an innovation is over the previous generation. As the relative advantage of an innovation increases, the rate of adoption for the innovation also increases. The diffusion of innovation theory (DOI) (Rogers, 2010) has its roots in sociology and has been in use since the 1960s to study an array of innovations ranging from agricultural tools to organizational innovations. Moore and Benbasat (1991) adapted innovation characteristics presented in Rogers (2010) and refined a set of variables that could be used to study individual technology acceptance. In an effort to operationalize the characteristics of innovation acceptance proposed by Rogers (2010), Moore and Benbasat (1991) developed the PCI model (Perceived Components of Innovation). A test of PCI by Plouffe et al. (2001) showed that relative advantage is the model's most powerful predictor of adoption intention. Agarwal and Prasad (1998) explored the role of these characteristics in predicting acceptance and found that there was modest support for the predictive validity of innovation characteristics. In terms of the overlapping variables with other models, the relative advantage and ease-of-use of DOT are similar to perceived usefulness and perceived ease-of-use of TAM, and the compatibility of this model is similar to the one used in the decomposed theory of planned behavior (DTPB) (Taylor \& Todd, 1995). Therefore, the hypothesis posits:

H7: The relative advantage has a positive influence on behavioral intention-to-use.

\subsection{Behavioral Intention to Use (IB)}

Behavioral intention-to-use refers to Ajzen's theory of planned behavior, which proposes a model that can measure how human actions are guided. Ajzen (1991) found that intentions are assumed to capture the motivational factors that influence behavior. They are indications of how hard people are willing to try, and of how much of an effort they are planning to exert in order to perform the behavior. As a general rule the stronger the intention to engage in a behavior, the more likely they will perform the behavior. It predicts the occurrence of a particular behavior, provided that behavior is intentional. Intentions are the precursors of actual use. In other words, as Cao et al. (2009) noted, an individual may be engaged in a less intended choice due to the presence of some constraints (behavioral control factors). Generally, intention tends to have a positive association with the actual choice of that behavior. So, in this study, the intention-touse is defined as the students' intentional use of Industry 4.0. All students in this study have indicated that they use the Industry 4.0 in studying nearly daily, often more than once a day. This study has indicated that the intention-touse is influenced by perceived usefulness, perceived ease of use, relative advantage. That is, the stronger an individual's behavioral intention, the more likely he/she is to perform the behavior. Taylor and Todd (1995) stated that thanks to the ability to predict intentions of use, predicting behavior is made possible. Thus, the hypothesis set out:

H8: Behavioral intention-to-use positively impacts actual use.

\subsection{Actual Use (AU)}

One's actual use of a technology system is influenced directly or indirectly by the user's intention-to-use. TAM also proposes that external factors affect intention and actual use through mediated effects on perceived usefulness and perceived ease of use (Davis, 1989). Several studies have examined TAM as a model to explain how people adopt and use e-learning. Selim (2003) stated that there was a need to investigate TAM with industry-based learning. He tested the relationships among perceived usefulness, perceived ease of use, and intention-to-use with university students using the structural equation modeling techniques of the LISREL program. He concluded that the model fit the collected data and that the usefulness and ease of use turned out to be good determinants of the acceptance and use efficient learning technology.

\subsection{Conceptual Model}

This study covered well-established research theories and models that have contributed to the development of the conceptual framework of technology adoption such as Consumer Acceptance of Technology (CAT) model, Theory of Reasoned Action (TRA) (Fishbein, 1967, Fishbein \& Ajzen, 1980), Theory of Planned Behavior (TPB) (Ajzen, 1991), Technology Adoption Model (TAM) (Davis, 1989, Davis et al., 1989) and the Unified Theory of Acceptance and Use of Technology (UTAUT) model (Venkatesh et al., 2013). This research, in conjunction with other studies examining the role of effect in predicting adoption intention (Bruner \& Kumar, 2005; Childers et al., 2001; Dabholkar \& Bagozzi, 2002), should serve as a caution to other consumer researchers that basing their behavioral predictions on cognition alone, as in the original TAM, may lead to significantly deteriorated prediction ability. 
The influence of industrial factors positively affects student learning, contributing to their own skills and knowledge development. This conceptual framework is modified by applying eight variables to determine the impact of occupation relevance, skills, facility conditions, and social influence, which apply Industry 4.0 on relative advantage and perceived usefulness. TAM suggests that perceived usefulness and relative advantage have a significant influence on behavioral intention-to-use and actual use (Davis, 1989; Mathieson, 1991; Moore \& Benbasat, 1991).

\section{Research Methods}

The conceptual model was developed on the basis of the hypotheses needed to be validated empirically using a mixed research method. In order to do this, a qualitative approach and quantitative approach were applied. Qualitative research was carried out by an in-depth interview with 15 participants. The quantitative approach was applied by using a questionnaire. The researchers recorded the in-depth interviews, then classified the elements as well as the considerations of the respondents, which would be used to make a pilot study and official questionnaire. A total of 15 respondents in the in-depth interview were to analyze each measurement item regarding essentiality and classified them into "not necessary", "useful, but non-essential" and "essential" category. The researchers also conducted desk research to have a more multi-dimensional view. The researchers made a survey in two stages, the first is a pilot study with 120 respondents, where SPSS 20 was used to eliminate the non-valid respondents; then, we built the official questionnaire. For testing the conceptual model and hypothesis, SPSS 20 and AMOS 20 software were utilized. This study applied non-probability with convenience sampling techniques. The study was conducted in many universities of economics in Ho Chi Minh City, Vietnam.

Data was collected using a self-administered questionnaire where the measurement of variables was based on existing measuring instruments. The form of questionnaire in this research applied a 5-point Likert scale ( $1=$ strongly disagree, $2=$ disagree, $3=$ neutral, $4=$ agree, $5=$ strongly agree). The researchers created a form by Google form, then distributed a questionnaire to the interviewees both electronic directly and indirectly. The administration process took 7 days. After a review of all respondents, out of 605 responses ( 305 by sending through social media, 300 by sending when meeting them directly) 584 responses were considered valid for further analysis.

\section{Results and Discussion}

\subsection{In-Depth Interview}

The eight constructs (variables) with 40 measurement items of conceptual model were developed from a theoretical basis to be tested through an in-depth interview by face content reliability and validity. The result showed that four measurement items were deleted from the questionnaire and 36 measurement items were qualified to go through the pilot study.

\subsection{Pilot Study}

A pilot study is a trial collection of data to detect weakness proxy data for the selection of a probability sample. To establish the reliability of the selected measurement instruments, this study has conducted a pilot study with the use of a convenience sample of 120 students studying in the HCMC University of Economics in Viet Nam. As evident in existing literature, this study has made use of content reliability to determine if the hypothesized items are actually measuring their variables. Theoretically, Cronbach's alpha of a loading 0.70 has been suggested by Nunnally and Bernstein (1994) as the cut-off criterion. Accordingly, 36 measurement items had correct item-total correlation higher than 0.3, so they were acceptable. The results have shown that the selected measurement items truly represent the hypothesized variables in the research framework. The 36 measurement items were reliable as shown in the questionnaire on the official study.

\subsection{Official Study}

\subsubsection{Descriptive Analysis}

The official study collected a total of 605 respondents, of which 21 invalid respondents were eliminated and 584 respondents were retained for analysis. The response rate was, therefore, $96.53 \%$. In the aggregate sample, $65.4 \%$ of respondents were females and $34.6 \%$ of respondents were males. $100 \%$ of them belonged to 13 Universities of Economics in Ho Chi Minh City, defined as people who were born between 1996 and 2000. These universities specialize in educating in the economics sector, with many students studying and gaining prestige. $25.8 \%$ of them are freshman, $24.4 \%$ are second-year students, $39 \%$ are third-year students, $7.1 \%$ are fourth-year students, and 3.7\% are others. For their majors, $14.9 \%$ are in business administration, $6.6 \%$ is an international business, $14.4 \%$ is finance-banking, $11.4 \%$ is accounting and audit, $19.4 \%$ are in marketing, the rest $33.3 \%$ is in general economics. All of them are living in $\mathrm{Ho}$ Chi Minh City, Vietnam.

\subsubsection{Reliability Test}

Before exploratory factor analysis (EFA), the measurements were tested for reliability by Cronbach's alpha coefficients. A higher Cronbach's alpha score indicated greater reliability and its accentual lower limit was 
0.7 (Nunnally \& Bernstein, 1994). The result of research showed that the Cronbach's alpha of constructs was from 0.899 to 0.903 . Corrected item-total correlation of items is bigger than 0.3 , so 36 measurement items were reliability, and continue to go through exploratory factor analysis.

\subsubsection{Exploratory Factor Analysis}

The measurement items were refined using exploratory factor analysis and poorly fitted items were excluded from the study. The results of the conceptual model, which included the standardized factor loadings, standard errors, variable reliabilities, and proportions of constructs extracted for each variable were statistically significant and sufficiently high to demonstrate that the indicators and their underlying variables were acceptable. In this study, the extraction method principal component analysis with Kaiser Normalization was used. The reliabilities and variable extracted for each latent variable revealed that the measurement model was reliable and valid. The result of the Kaiser-Meyer-Olkin Measure of Sampling Adequacy $=0.847$. Extraction sums of squared loading $=63.59 \%$. Bartlett's Test of Sphericity $\mathrm{Sig}=0.000$. The results of the factor analysis showed that the dimension proposed for each variable had been demonstrated as acceptable. The factor loading of 36 measurement items of eight variables ranging from 0.526 to 0.939 were greater than the conventional value of 0.5 and was acceptable (Hair et. al, 2006) (see Table 1).

Table 1: Pattern Matrix - EFA

\begin{tabular}{|c|c|c|c|c|c|c|c|c|}
\hline \multirow{2}{*}{ Measurement itemt } & \multicolumn{8}{|c|}{ Factor } \\
\hline & 1 & 2 & 3 & 4 & 5 & 6 & 7 & 8 \\
\hline IB1 & .878 & & & & & & & \\
\hline IB4 & .872 & & & & & & & \\
\hline IB3 & .759 & & & & & & & \\
\hline IB5 & .755 & & & & & & & \\
\hline IB2 & .618 & & & & & & & \\
\hline FC2 & & .817 & & & & & & \\
\hline FC1 & & .812 & & & & & & \\
\hline FC4 & & .748 & & & & & & \\
\hline FC3 & & .707 & & & & & & \\
\hline FC5 & & .526 & & & & & & \\
\hline $\mathrm{SI} 3$ & & & .742 & & & & & \\
\hline $\mathrm{SI} 2$ & & & .712 & & & & & \\
\hline $\mathrm{SI} 4$ & & & .683 & & & & & \\
\hline SI5 & & & .676 & & & & & \\
\hline SI1 & & & .649 & & & & & \\
\hline PU2 & & & & .742 & & & & \\
\hline PU3 & & & & .728 & & & & \\
\hline PU1 & & & & .728 & & & & \\
\hline PU4 & & & & .677 & & & & \\
\hline PU5 & & & & .573 & & & & \\
\hline OC1 & & & & & .795 & & & \\
\hline OC3 & & & & & .666 & & & \\
\hline $\mathrm{OC2}$ & & & & & .642 & & & \\
\hline OC5 & & & & & .632 & & & \\
\hline OC4 & & & & & .616 & & & \\
\hline AR3 & & & & & & .760 & & \\
\hline AR5 & & & & & & .759 & & \\
\hline AR4 & & & & & & .719 & & \\
\hline AR2 & & & & & & .708 & & \\
\hline SK1 & & & & & & & .788 & \\
\hline SK2 & & & & & & & .766 & \\
\hline SK3 & & & & & & & .561 & \\
\hline SK5 & & & & & & & .557 & \\
\hline $\mathrm{AU} 4$ & & & & & & & & .939 \\
\hline $\mathrm{AU} 2$ & & & & & & & & .937 \\
\hline
\end{tabular}




\subsubsection{Confirmatory Factor Analysis (CFA)}

The research follows a two steps approach. First, the measurement model is estimated based on the confirmatory factor analysis. Second, the researchers analyze the structural equation model and estimate the path coefficients, both for the direct as well as for the mediated effects (Dong \& Phuong, 2018). To begin with, fit indices that the data fit the hypothesized measurement model well. The results of CFA showed an acceptable fit of data $($ Chi-square $=1166.731 ; \mathrm{df}=$ 528; $\mathrm{P}=000 ;$ Chi-square $/ \mathrm{df}=2.210 ; \mathrm{IFI}=0.951 ; \mathrm{GFI}=890$; $\mathrm{TFI}=0.944 ; \mathrm{CFI}=0.951 ; \mathrm{RMSEA}=0.046$ ). This study also explored how researchers report models fit in light of the divergent perspectives present in the literature. All factors loading were highly 0.5 significant on the expected variables (Geyskens et al., 2006). Correlations between factors were also estimated in the confirmatory factor analysis. The factor structure and the factor loadings obtained in previous exploratory factor analysis with the same scale and items (Ozturk et al., 2010) showed resemblance to those obtained in the present confirmatory factor analysis, exhibiting consistency across the study, thus, providing additional evidence for cross-validation of the scale.

Confirmative factor analysis overall model Cronbach's alpha is a measure used to assess the reliability, or internal consistency, of a set of scale or test items. As pointed out earlier, the number of test items, item inter-relatedness, and dimensionality affect the value of alpha. There are different reports about the acceptable values of alpha, ranging from 0.70 to 0.95 . In this study, the Cronbach's alpha scores are from 0.722 to 0.996 , therefore all items should be retained. Composite reliability values from 0.743 to 0.996 , measurement item achieved convergent validity if standardized regression weighted $>0.5$ and significant p-value $<0.05$ (Anderson \& Gerbring, 1988).

The results of this study showed that all standardized regression weights of 36 measurement items were from
0.506 to 1.006 , bigger than 0.5 . Therefore, they were convergent validity. High-quality tests are important to evaluate the reliability of data supplied in an examination or a research study. Alpha is a commonly employed index of test reliability. Alpha is affected by the test length and dimensionality. A high value of alpha (> 0.90 ) may suggest redundancies and show that the test length should be shortened. All correlation coefficient between variables with other variable were $<0.9$ and all P-value was $<0.05$ so that the correlation coefficient of each pair of concepts were different from 1 to $95 \%$ confidence level (correlation coefficient which you could infer that it followed $<1$ ) therefore, the variables were discriminant validity. The results showed the values of composite reliable and variable extracted of variables were greater than 0.5 (Hair, 2000). Therefore, this variable had satisfactory reliability and variable extracted aggregate. Cronbach's alpha coefficient reliability of the variables that had values greater than 0.6 scales should also meet the requirements of reliability coefficients. The correlation coefficient results showed that p-value $=0.000$ of each pair of variable different from the one at the $95 \%$ confidence level, the correlation coefficients were less than 1 . Therefore, the variables gained valuable distinction (see Table 2).

\subsubsection{Structural Equation Model}

This study's objective was to identify the relationships between occupation relevance, skills, facility condition, social influence, as well as relative advantage, perceived usefulness, behavioral intention-to-use, and actual use. To achieve this objective, the SEM was employed to test the interrelationships among all the research constructs, and to compare the modeled relationships with the observed scores. The structural equation model proposed is shown in Figure 1.

Table 2: Reliability Variables

\begin{tabular}{|l|c|c|c|c|c|}
\hline Variable & $\begin{array}{c}\text { Cronbach's } \\
\text { Alpha }\end{array}$ & $\begin{array}{c}\text { Composite } \\
\text { Reliability }\end{array}$ & $\begin{array}{c}\text { Average variable } \\
\text { extracted }\end{array}$ & $\begin{array}{c}\text { Convergent } \\
\text { validity }\end{array}$ & $\begin{array}{c}\text { Discriminant } \\
\text { validity }\end{array}$ \\
\hline IB & 0.883 & 0.846 & 0.549 & Accepted & Accepted \\
\hline FC & 0.841 & 0.841 & 0.521 & Accepted & Accepted \\
\hline SI & 0.813 & 0.819 & 0.477 & Accepted & Accepted \\
\hline PU & 0.801 & 0.788 & 0.428 & Accepted & Accepted \\
\hline OC & 0.788 & 0.789 & 0.438 & Accepted & Accepted \\
\hline AR & 0.834 & 0.837 & 0.563 & Accepted & Accepted \\
\hline SK & 0.722 & 0.743 & 0.428 & Accepted & Accepted \\
\hline AU & 0.996 & 0.996 & 0.993 & Accepted & Accepted \\
\hline
\end{tabular}




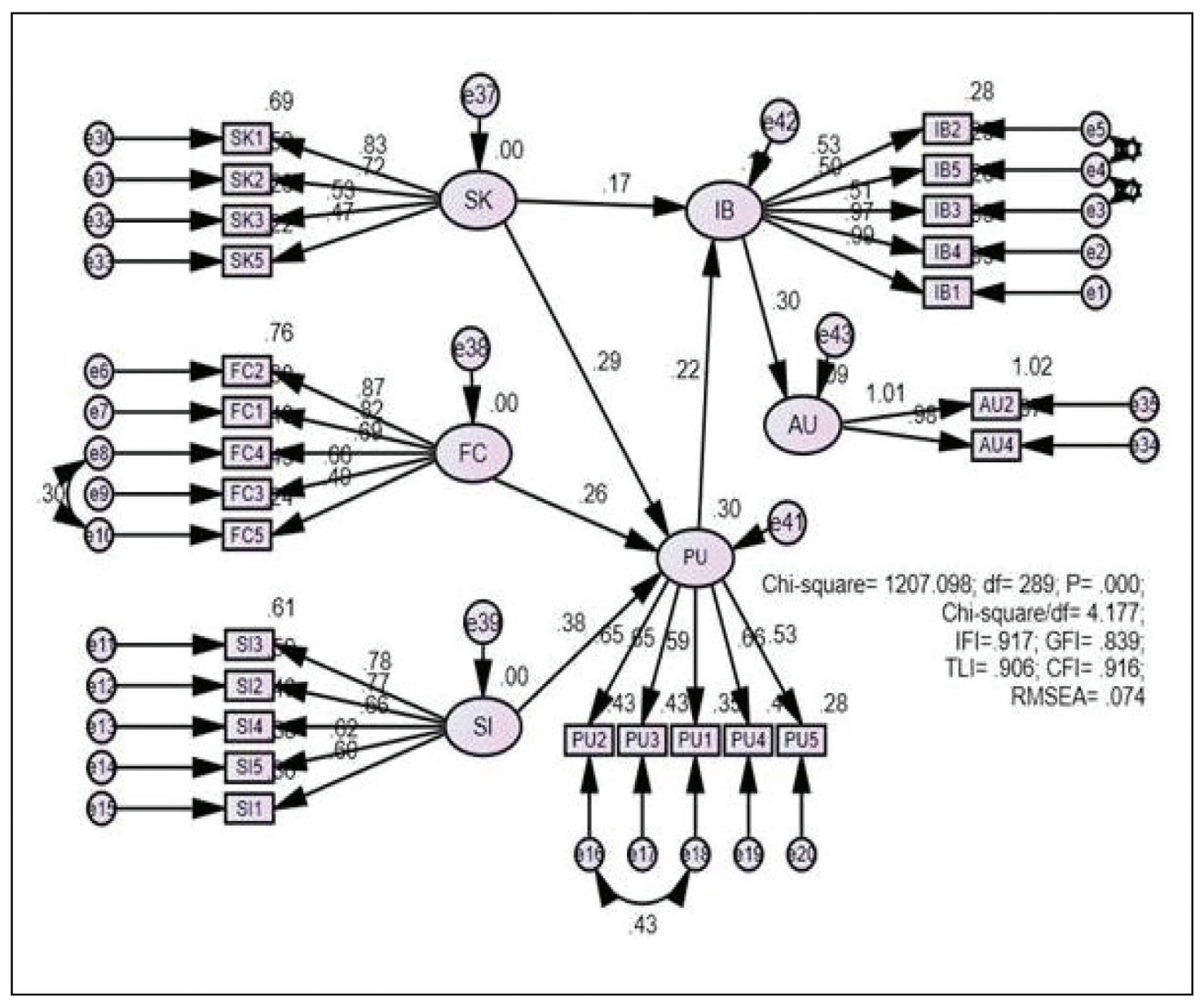

Figure 1: Structural Equation model Analysis

The likelihood ratio chi-squared test assessed the overall model fit. Chi-squared was significant in this case (Chisquared $=1207.098 ; \mathrm{df}=289, \mathrm{p}=0.00)$. Chi-squared $/ \mathrm{df}=$ 4.177. Other indices of model fit included all expected the recommended threshold level of 0.9 , except GFI $<0.9$ (TLI $=$ 0.906, $\mathrm{CFI}=0.916, \mathrm{IFI}=0.917$; $\mathrm{GFI}=0.839)($ Figure 1$)$. The root means the square error of approximate (RMSEA) described the discrepancy between the proposed model and the population covariance matrix. RMSEA was 0.074 , below the recommend $<0.08$ level (McKnight, Choudhury \& Kacmar, 2002; Geffen et al., 2000). All the parameters in the SEM model for the P-value were less than 0.05, so the relationships were significant in the model. Thus, the overall model had a good fit. Therefore, we could proceed to examine the path coefficients of the structural model.

The result showed that the initial part of this output contains the familiar Estimate, S.E. (standard error), and C.R. (Critical Ratio, the estimate divided by its standard error) quantities that are computed assuming a normal distribution of the observed variables. Notice that each covariance is statistically significant. All of the variances were positively correlated (see Table 3).

\subsubsection{Bootstrap Estimate Model}

Usually in the quantitative research, so as to test the reliability of the estimates, researchers have to divide the two samples. The first half is used for estimating the model parameters and the other half is for retesting. The other way is to repeat the study using a different sample. The Bootstrap method was suitable to replace (Schumacker \& Lomax, 2010). Bootstrap is a repeated sampling method that has replaced the original model in which, as the population. This study used bootstrap methods (Schumacker \& Lomax, 2010) with the number of repeated samples $N=1000$ to estimate the model in practice. The CR (bias/SE-bias) absolute value was less than 2.0. Thus, the researchers could conclude that the estimates in the models can be trusted and fit. 
Table 3: Regression Weights

\begin{tabular}{|c|c|c|c|c|c|c|c|}
\hline \multicolumn{3}{|c|}{ Parameter } & \multirow{2}{*}{$\begin{array}{c}\text { Standardized Regression Weights } \\
.263\end{array}$} & \multirow{2}{*}{$\begin{array}{c}\text { Estimate } \\
.198\end{array}$} & \multirow{2}{*}{$\begin{array}{l}\text { S.E. } \\
.037\end{array}$} & \multirow{2}{*}{$\begin{array}{c}\text { C.R. } \\
5.378\end{array}$} & \multirow{2}{*}{$\frac{\mathbf{P}}{* * *}$} \\
\hline PU & $<--$ & $\mathrm{FC}$ & & & & & \\
\hline PU & $<--$ & SI & .383 & .357 & .050 & 7.162 & *** \\
\hline PU & $<--$ & SK & .292 & .223 & .040 & 5.556 & $* * *$ \\
\hline IB & $<--$ & SK & .170 & .194 & .055 & 3.534 & *** \\
\hline IB & $<--$ & PU & .221 & .329 & .075 & 4.370 & $* * *$ \\
\hline$A U$ & $<---$ & IB & .296 & .303 & .042 & 7.273 & $* * *$ \\
\hline
\end{tabular}

Note: ${ }^{* * *} P$-value $<0.001$

Table 4: Summary of Hypothesis Testing

\begin{tabular}{|l|l|c|}
\hline \multicolumn{1}{|c|}{ Hypothesis } & Results of Testing \\
\hline H1 & Occupation relevance will have a positive effect on Relative Advantage. & Rejected \\
\hline H2 & Skills has a positive influence on Perceived Usefulness & Supported \\
\hline H3 & Facility Conditions has a positive influence on Perceived Usefulness & Supported \\
\hline H4 & Social influence has a positive influence on Perceived Usefulness. & Supported \\
\hline H5 & Skills has a positive influence on Behavioral Intention-to-Use & Rejected \\
\hline H6 & The Perceived Usefulness has positive significant on Behavioral Intention-to-Use & Supported \\
\hline H7 & The Relative Advantage has a positive influence on Behavioral Intention-to-Use & Supported \\
\hline H8 & Behavioral Intention to Use positively impacts Actual Use. & Supported \\
\hline
\end{tabular}

\subsubsection{Model Fitting and Hypothesis Testing}

The final model-fit statistics indicated that the overall variables were supported. All the hypotheses paths were significant, significant at less than the $\mathrm{p}<0.01$ level, except H1 and H5. Overall, all the path coefficient-related hypotheses were supported from 0.171 to 0.383 . The actual use was explained by $8.7 \%\left(\mathrm{R}^{2}=0.087\right)$. An important result showed that social influence strongly impacted perceived usefulness with the path coefficient-related $=0.383$. Skills influenced not only perceived usefulness but also behavioral intention-to-use with the path coefficient-related $=0.171$ (see Table 4).

\section{Conclusions}

The theoretical contribution of this study was to identify the impact of facility conditions, skills, and social influence on actual use Industry 4.0 of students in Ho Chi Minh City, Viet Nam. Based on the SEM model and finally described in this study, there are some primary conclusions: skills, facility conditions, social influence are independent variables. They impact actual use through two mediating variables: perceived usefulness and behavioral intention-to-use. Two variables: occupation relevance and relative advantage were not accepted in the conceptual model based on variable elimination. This study has shown that skill influences, not only perceived usefulness, but also behavioral intention-touse. The study also discovers an exciting fact that facility conditions and social influence variables have an impact on perceived usefulness, behavioral intention-to-use, and actual use.

\section{References}

Agarwal, R., \& Prasad, J. (1998) A Conceptual and Operational Definition of Personal Innovativeness in the Domain of Information Technology. Information Systems Research, 9, 204-224. http://dx.doi.org/10.1287/isre.9.2.204

Ajzen, I. (1991). The theory of planned behavior. Organizational Behavior and Human Decision Processes, 50(2), 179-211.

Ajzen, I., \& Fishbein, M. (1980). Understanding attitudes and predicting social behavior. Englewood Cliffs, NJ: PrenticeHall.

Alibekova, G., Tleppayev, A., Medeni, T. D., \& Ruzanov, R. (2019). Determinants of Technology Commercialization Ecosystem for Universities in Kazakhstan. Journal of Asian Finance, Economics and Business, 6(4), 271-279. https://doi. org/10.13106/jafeb.2019.vol6.no4.271 
Aypay, A., Celik, H., \& Aypay, A. (2012). Technology acceptance in education: A study of pre-service teachers in turkey. The Turkish Online of Educational Technology, 11(4), 264-272.

Bergeron, F., Rivard, S., \& De Serre, L. (1990). Investigating the support role of the information center. MIS Quarterly, 14, 247-259.

Brief, A. P., \& Roberson, L. (1989). Job Attitude Organization: An Exploratory Study. Journal of Applied Social Psychology, 19(9), 717-727.

Bruner II, G. C., \& Kumar, A. (2005). Explaining consumer acceptance of handheld Internet devices. Journal of Business Research, 58(5), 553-558.

Cao, X., Mokhtarian, P. L., \& Handy, S. L. (2009). Examining the Impacts of Residential Self-Selection on Travel Behaviour: A Focus on Empirical Findings. Journal of Transport Reviews, 29(3), 359-395.

Childers, T. L., Carr, C. L., Peck, J., \& Carson, S. (2001). Hedonic and utilitarian motivations for online retail shopping behavior. Journal of Retailing, 77(4) 511-535.

Chryssolouris, G., Mavrikios, D., \& Mourtzis, D. (2013). Manufacturing systems: skills \& competencies for the future. Procedia CIRp, 7(2013), 17-24.

Concannon, F., Flynn, A., \& Campbell, M. (2005). What campusbased students think about the quality and benefits of e-learning. British Journal of Educational Technology, 36(3), 501-512.

Dabholkar, P. A., \& Bagozzi, R. P. (2002). An attitudinal model of technology-based self-service: moderating effects of consumer traits and situational factors. Journal of the Academy of Marketing Science, 30(3), 184-201.

Davis, F. D. (1989). Perceived usefulness, perceived ease of use, and user acceptance of information technology, MIS Quarterly, 13(3), 319-340.

Davis, F. D., Bagozzi, R. P., \& Warshaw, P. R. (1989). User acceptance of computer technology: A comparison of two theoretical models. Management Science, 35(8), 982-1003.

Dong, L. N. T., \& Phuong, N. N. D. (2018). Organizational Justice, Job Satisfaction and Organizational Citizenship Behavior in Higher Education Institutions: A Research Proposition in Vietnam. Journal of Asian Finance, Economics, and Business, 5(3), 113-119. http://doi.org/10.13106/jafeb.2018.vol5.no3.113

Fishbein, M. (1967). Attitude and the prediction of behavior. In: M. Fishbein (Ed.), Readings in attitude theory and measurement (pp. 477-492). New York, NY: Wiley.

Geffen, D., Straub, D. W., \& Boudreau, M. C. (2000). Structural equation modeling and regression: Guidelines for research practice. Communications of the Association for Information Systems, 4(7), 1-79.

Gentry, L., \& Calantone, R. (2002). A comparison of three models to explain shop-bot use on the web. Psychology \& Marketing, 19(11), 945-956.

Geyskens, I., Steenkamp, J. B. E., \& Kumar, N. (2006). Make, buy, or ally: A transaction cost theory meta-analysis. Academy of Management Journal, 49(3), 519-543.
Hair, J. F., Black, W. C., Babin, B. J., Anderson, R. E., \& Tatham, R. (2006). Multivariate data analysis. Upper Saddle River, NJ: Prentice-Hall.

Hair, J. F., Bush, R. P., \& Ortinau, D. J. (2000). Marketing research: A practical approach for the new millennium. Burr Ridge, IL: Irwin Professional Publishing.

Hall, D., \& Mansfield, R. (1975). Relationships of Age and Seniority with Career Variables of Engineers and Scientists. Journal of Applied Psychology, 60(3), 201-210.

Jadhav, V., Seetharaman, A., \& Rai, S. (2017). Employee expectation to demonstrate innovative work behaviour in Asia. Journal of Asian Finance, Economics and Business, 4(1), 67-78. http://dx.doi.org/10.13106/jafeb.2017.vol4.no1.67

Kim, S. Y., Kim, J. W., Ko, Y. S., Koo, J. E., Chung, H. Y., \& Lee-Kim, Y. C. (2003). Changes in lipid peroxidation and antioxidant trace elements in serum of women with cervical intraepithelial neoplasia and invasive cancer. Nutrition and Cancer, 47(2), 126-130.

Kocaleva, M., Stojanovic, I., \& Zdravev, Z. (2015). Model of e-learning acceptance and use for teaching staff in Higher Education Institutions. International Journal of Modern Education and Computer Science, 7(4), 23-31.

Mathieson, K. (1991). Predicting user intentions: Comparing the technology acceptance model with the theory of planned behavior. Information Systems Research. Information Systems Research, 2(3), 173-191.

McKnight, D. H., Choudhury, V., \& Kacmar, C. (2002). Developing and validating trust measures for e-commerce: An integrative typology. Information Systems Research, 13(3), 334-359.

Mejía, N. A. (2015). Smart Working Environments, possible future scenarios, and technology adoption implications. Working Paper, Institute of Media and Communication Science, Technische Universität Ilmenau. DOI: 10.13140/ RG.2.1.2520.2088

Moore, G. C., \& Benbasat, I. (1991). Development of an instrument to measure the perceptions of adopting an information technology innovation. Information Systems Research, 2(3), 192-222. http://dx.doi.org/10.1287/isre.2.3.192.

Nguyen, X. T. (2018). The Impact of Hallyu 4.0 and Social Media on Korean Products Purchase Decision of Generation C in Vietnam. Journal of Asian Finance, Economics and Business, 5(3), 81-93. http://doi.org/10.13106/jafeb.2018.vol5.no3.81

Nguyen, X. T., \& Luu, Q. K. (2020). Factors Affecting Adoption of Industry 4.0 by Small- and Medium-Sized Enterprises: A Case in Ho Chi Minh City, Vietnam. Journal of Asian Finance, Economics and Business, 7(6), 255-264. https://doi. org/10.13106/jafeb.2020.vol7.no6.255

Nguyen, X. T. (2019). Factors Impacting on Korean Consumer Goods Purchase Decision of Vietnam's Generation Z. Journal of Distribution Science 17(10), 61-71.

Nunnally, J. C., \& Bernstein, I. H. (1994). Psychometric theory (3 ${ }^{\text {rd }}$ ed). New York, NY: McGraw-Hill. 
Osswald, S., Wurhofer, D., Trösterer, S., Beck, E., \& Tscheligi, M. (2012, October). Predicting information technology usage in the car: towards a car technology acceptance model. In: Proceedings of the 4th International Conference on Automotive User Interfaces and Interactive Vehicular Applications (pp. 51-58).

Ozturk, I., Aslan, A., \& Kalyoncu, H. (2010). Energy consumption and economic growth relationship: Evidence from panel data for low and middle income countries. Energy Policy, 38(8), $4422-4428$.

Plouffe, C. R., Hulland, J. S., \& Vandenbosch, M. (2001). Richness versus parsimony in modeling technology adoption decisions - understanding merchant adoption of a smart cardbased payment system. Information Systems Research, 12(2), 208-222.

Polson, P. G. (1987). A quantitative theory of human-computer interaction. In: Interfacing thought: Cognitive aspects of human-computer interaction (pp. 184-235).

Polson, P. G., \& Kieras, D. E. (1985). A quantitative model of the learning and performance of text editing knowledge. $A C M$ SIGCHI Bulletin, 16(4), 207-212.

Rogers, E. M. (2010). Diffusion of innovations. New York, NY: Simon and Schuster.

Schurnacker, R. E., \& Lomax, R. G. (2010). A beginner's guide to structural equation modelling ( $3^{\text {rd }}$ ed.). New York, NY: Routledge.

Selim, H. M. (2003). An empirical investigation of student acceptance of course websites. Computers \& Education, 40(4), 343-360.
Shore, L., Power, V., De Eyto, A., \& O'Sullivan, L. W. (2018). Technology acceptance and user-centred design of assistive exoskeletons for older adults: A commentary. Robotics, 7(1), 3. https://doi.org/10.3390/robotics7010003

Taylor, S., \& Todd, P. A. (1995). Understanding information technology usage: A test of competing models. Information Systems Research, 6(2), 144-176.

Van Deursen, A. J., Helsper, E. J., \& Eynon, R. (2016). Development and validation of the Internet Skills Scale (ISS). Information, Communication \& Society, 19(6), 804-823.

Van Deursen, A. J. A. M., \& Van Dijk, J. A. G. M. (2016). Modeling traditional literacy, internet skills and internet usage: an empirical study. Interacting with Computers, 28(1), 13-26.

Van Deursen, A. J. A. M., \& Mossberger, K. (2018). Anything for anyone? A new digital divide in Internet-of-Things skills. Policy Internet, 10(2), 122-140.

Venkatesh, V., Morris, M. G., \& Davis, F.D. (2003). User acceptance of information technology: Toward a unified view. MIS Quarterly, 27(3), 425-478.

Venkatesh, V., \& Davis, F. D. (2000). A theoretical extension of the technology acceptance model: Four longitudinal field studies. Management Science, 46(2), 186-204.

Venkatesh, V., Brown, S. A., \& Bala, H. (2013). Bridging the qualitative-quantitative divide: Guidelines for conducting mixed methods research in information systems. MIS Quarterly, $37(1), 21-54$. 